Х. Б. М. мухаммедов, Н.Н.Шевлюк,

А. А. Третьяков, А. А. Стадников, С.Б. Фадеев

МЕТОД ЗАКРЫТИЯ ОСТАТОЧНОЙ ПОЛОСТИ
КОМПОЗИТНЫМ МАТЕРИАЛОМ «ЛИТАР»
В КОМБИНАЦИИ С АНТИБИОТИКОМ
ПРИ ХРОНИЧЕСКОЙ ЭМПИЕМЕ ПЛЕВРЫ
И ОСОБЕННОСТИ РЕПАРАТИВНОГО ГИСТОГЕНЕЗА

Оренбургский государственный медицинский университет,

Российская Федерация, 460000, Оренбург, Советская ул., 6

Изучены особенности репаративного гистогенеза во время ликвидации ригидной остаточной полости при хронической эмпиеме плевры композитным материалом. Проведен эксперимент по моделированию ограниченной хронической эмпиемы плевры, и определена возможность использования композитного материала «ЛитАр» в комбинации с антибиотиком для ликвидации ригидной остаточной полости при хронической эмпиеме плевры. Полученные данные показали, что данная комбинация ускорила васкулогенез, оптимизировала пролиферацию и цитодифференцировку клеток фибробластического дифферона, в результате которой в композитный материал мигрировало большое количество дифференцированных фибробластов, формирующих на месте ликвидированной полости рыхлую неоформленную соединительную ткань. Библиогр. 12 назв. Ил. 4.

Ключевые слова: остаточная полость плевры, эмпиема, регенерация, соединительная ткань, композитный материал.

\title{
METHOD OF CLOSING THE RESIDUAL CAVITY WITH COMPOSITE MATERIAL 'LITAR' IN COMBINATION WITH AN ANTIBIOTIC FOR CHRONIC PLEURAL EMPYEMA AND FEATURES OF REPARATIVE HISTOGENESIS
}

\author{
Kh. B. M. Mukhammedov, N. N. Shevlyuk, A. A. Tretyakov, A. A. Stadnikov, S. B. Fadeev
}

Medical University "Orenburg State Medical University”

of Ministry of Health of the Russian Federation,

6, Sovetskaya ul., Orenburg, 460000, Russian Federation

Our research examines the features of reparative histogenesis in liquidation of rigid residual cavity in chronic pleural empyema by means of a composite material. An experiment was conducted using 30 laboratory rats to model limited chronic pleural empyema (formed by implantation in the right half of the chest cavity a silicone bead with a $9 \mathrm{~mm}$ diameter) and determine the use of the composite material "LitAr" in combination with an antibiotic to eliminate a rigid residual cavity in chronic pleural empyema. The cavity over the course of 20 days observation was infected with the introduction of $0.5 \mathrm{ml}$ of overnight culture suspension of $10^{5} \mathrm{CFU}$ of Klebsiella pneumonia (strain GISCO № 278).

To create a model of limited chronic empyema it took 38 days. Then the infected cavity was filled with composite material and the antibiotic cefazolin was administered intramuscularly in the dose of $20 \mathrm{mg} / \mathrm{kg}$ two times per day for 10 days. The area subjected to sealing composite material was then excised for subsequent morphological study. The data showed that the combination of composite "LitAr" antibiotic accelerated vasculogenesis, optimized cell proliferation and fibroblast cytodifferentiation differon. This resulted in the migration of a large number of differentiated fibroblasts to the composite material. These formed on the site of the liquidated cavity as loose irregular connective tissue. Refs 12 . Figs 4.

Keywords: residual pleural cavity, empyema, regeneration, connective tissue, composite material.

(C) Санкт-Петербургский государственный университет, 2017 


\section{Введение}

Эмпиема плевры остается актуальной медицинской проблемой из-за распространенности заболевания, длительной госпитализации больных, повышенного риска смертности. У большей части больных эмпиема плевры возникает из-за воспалительных процессов в легких: на фоне острой пневмонии - $4 \%$, абсцесса легкого - 9-11\%, при гангрене легкого - 80-95\%, как следствие ранений и травм органов грудной клетки - 6-12\% [1, 2]. Если лечение эмпиемы плевры оказалось неэффективно, то она приобретает хроническое течение [3], вследствие чего создается ригидная остаточная полость с инфекционным процессом в ней. Задачи хирургического лечения сводятся к устранению очага инфекционного процесса и ликвидации стойкой остаточной плевральной полости $[4,5]$. Однако декортикацию легкого и плеврэктомию в чистом виде можно провести далеко не всем пациентам. Часто эту операцию комбинируют с дополнительными вмешательствами - резекцией пораженных отделов легкого, реампутацией культи бронха, корригирующей торакопластикой $[6,7]$. Если произошли необратимые изменения в коллабированных отделах легкого, то даже после декортикации отмечается потеря способности к расправлению. В этом случае ликвидировать ригидную остаточную полость можно лишь технически сложной торакопластикой [8].

В связи с этим заслуживают внимания попытки ликвидации стойкой остаточной плевральной полости с помощью пломбирования ее различными материалами $[9,10]$. Одним из материалов, который может быть использован для ликвидации остаточной полости хронической эмпиемы плевры, является гидроксоапатитколлагеновый биодеградируемый композит «ЛитАр». Данный композит является цитоактивным наноразмерным материалом, предназначенным для восполнения дефектов тканей (фирма-изготовитель - ООО НПП «СердоЛит»). Изучение морфологических изменений в области внедрения биокомпозита в остаточные полости представляет определенный интерес в регенеративной хирургии. Многочисленные работы по применению данного композита говорят о том, что «ЛитАр», являясь наноразмерным биополимером, воздействует на полипотентные клетки организма и те, в свою очередь, в более короткие сроки способствуют регенерации того органа, куда он был имплантирован, вызывая замещение дефекта органотипическим регенератором $[11,12]$. Известно, что не все ткани обладают одинаковыми возможностями к полному восстановлению, но иногда этого и не требуется. В некоторых случаях для ликвидации очагов хронической инфекции благоприятным является их полное замещение соединительной тканью.

Целью исследования явилось изучение особенностей закрытия ригидной остаточной полости при хронической эмпиеме плевры с использованием пломбировочного материала «ЛитАр» в комбинации с антибиотиком.

\section{Материалы и методы исследования}

Опыт проведен на 30 лабораторных белых крысах - самцах линии Вистар массой 180-250 г. Эксперимент состоял из двух этапов. На первом этапе на всех животных моделировали ограниченную хроническую эмпиему плевры.

Моделирование асептической ограниченной полости в правой половине грудной клетки осуществляли путем имплантации в нее латексного шарика. Под эфир- 
ным эндотрахеальным наркозом с искусственной вентиляцией легких, которую осуществляли через введенный в отверстие в трахее подключичный катетер, выполняли боковую торакотомию в седьмом межреберье справа. Длина разреза 1,5 см. По вскрытию плевральной полости в реберно-диафрагмальный синус вводили латексный шарик диаметром 1 см, обработанный снаружи 70\%-м раствором этилового спирта с тальком. Шарик фиксировали викриловой лигатурой к грудной стенке и ушивали торакотомическую рану с восстановлением герметичности плевральной полости. Отверстие в трахее ушивали атравматической нитью. Через 20 суток после введения латексного шарика в плевральную полость производили реторакотомию разрезом, длина которого составила 1,0 см, латексный шарик извлекали из полости. Торакотомическая рана ушивалась. В сформированную асептическую полость на 20-х сутках эксперимента пункционно вводилось 0,5 мл взвеси суточной культуры Klebsiella pneumonia $10^{5}$ КОЕ (штамм ГИСК № 278 из музейной коллекции Института клеточного и внутриклеточного симбиоза УрО РАН). Местное лечение эмпиемы этим животным проводилось традиционным способом - пункциями инфицированной полости, промыванием ее $1 \%$-м раствором диоксидина и введением внутримышечно антибиотика цефазолина в дозе 10 мг/кг два раза в сутки. На создание модели ограниченной хронической эмпиемы плевры потребовалось 38 суток.

На втором этапе полость, сформированную по описанной методике, диаметром около 1 см на 38-е сутки эксперимента заполняли композитом «ЛитАр» $[9,11,12]$ размером 0,25 см и вводили внутримышечно антибиотик цефазолин в дозе 20 мкг/кг два раза в сутки в течение 10 дней. Все операции проводили при соблюдении правил асептики и антисептики. Животных выводили из опыта путем передозировки эфира: на 3, 7, 14, 21 и 30-е сутки с момента имплантации «ЛитАр» с антибиотиком. При проведении экспериментов соблюдали требования, содержащиеся в Федеральном законе от 24.04.1995 N 52-Ф3 (ред. от 03.07.2016) «О животном мире», а также положения Европейской конвенции по защите позвоночных, используемых для экспериментальных и иных научных целей. Проведение исследований разрешено локальным этическим комитетом Оренбургской государственной медицинской академии Минздрава России 1 октября 2014 г. Для светооптических исследований материал фиксировали в 10\%-м нейтральном растворе формалина, дегидратировали в спиртах возрастающей крепости и заливали в парафин. Парафиновые срезы толщиной 5-7 мкм окрашивали гематоксилином Майера и эозином, а также использовали окраску по Ван Гизону.

\section{Результаты и их обсуждение}

Через трое суток визуально при клиническом осмотре было выявлено, что композит разбухает и заполняет все пространство остаточной полости. Анализ гистологических препаратов показал, что уже на третьи сутки со стороны капсулы, ограничивающей полость, вначале в периферические, а затем и в центральные участки пространства, заполненного композитным материалом, происходит активная миграция клеточных элементов крови и соединительной ткани, преимущественно гранулоцитов, лимфоцитов и малодифференцированных фибробластов (рис. 1, здесь и далее использовано увеличение окуляра - в 10, объектива - в 40 раз). 
На седьмые сутки эксперимента в центральных и периферических участках пространства, заполненного композитным материалом в комбинации с антибиотиком, отмечается значительное возрастание пролиферации и цитодифференцировки клеток фибробластического дифферона, в результате которой в композитном материале наблюдается большое количество дифференцированных фибробластов. В результате синтетической деятельности фибробластов в межклеточном пространстве в большом количестве располагаются коллагеновые волокна и основное аморфное вещество (рис. 2).

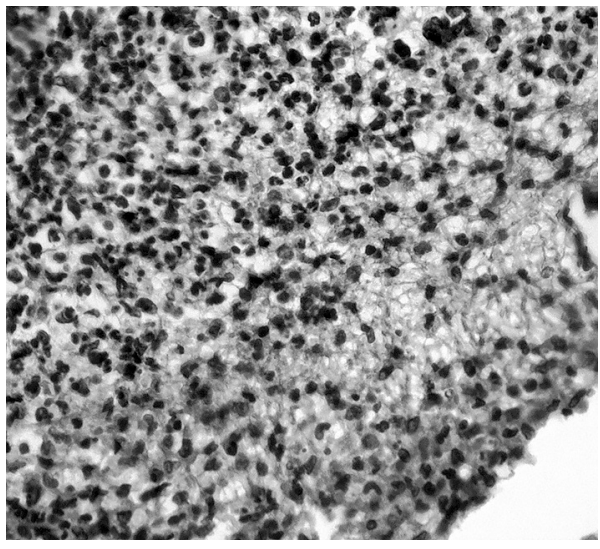

Рuc. 1 Фрагмент остаточной полости при хронической эмпиеме плевры крысы, заполненной композитным материалом «ЛитАр» в комбинации с антибиотиком. Стадия третьих суток эксперимента (увеличение окуляра - в 10, объектива в 40 раз)

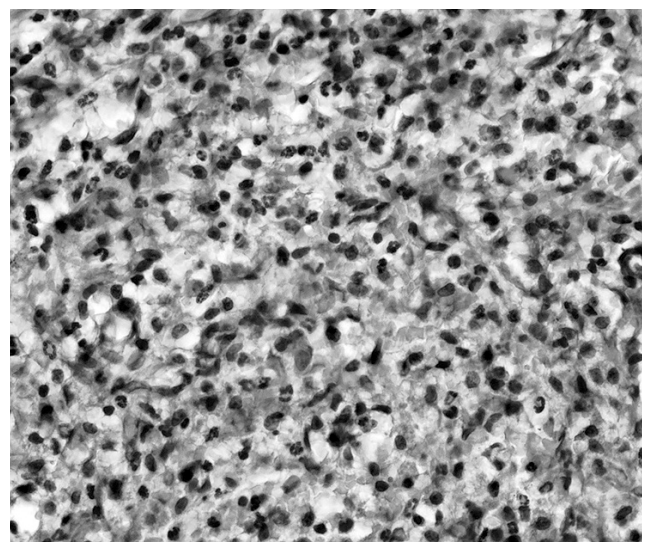

Puc. 2. Фрагмент остаточной полости при хронической эмпиеме плевры крысы, заполненной композитным материалом «ЛитАр» в комбинации с антибиотиком. Стадия седьмых суток эксперимента (увеличение окуляра - в 10, объектива - в 40 раз)

Во вновь образованной соединительной ткани видно большое количество новообразованных сосудов. Процессы активного фибриллогенеза и ангиогенеза наиболее выражены с конца первой недели и до начала третьей недели эксперимента. В результате активного синтеза компонентов межклеточного вещества к 14-м суткам эксперимента на месте полости формируется рыхлая неоформленная соединительная ткань. В этой вновь сформированной соединительной ткани наблюдается уменьшение лейкоцитарной инфильтрации (рис. 3).

На 21-е и 30-е сутки с момента имплантации композита и антибиотикотерапии послеоперационный рубец был состоятельным, гладким, а кожа в этой области рубца - эластичной и подвижной. Деформации грудной клетки не выявлено. При иссечении правой половины грудной клетки отмечено плотное спаивание с костальной плеврой мягко-эластического соединительнотканного образования (на разрезе оно имело обычный цвет, мягко-эластическую плотность, однородную структуру, без очагов скопления гноя на месте остаточной полости). Плевральные листки - гладкие, блестящие; легкое не спаяно с образованием, воздушное. Выпота не выявлено. На месте полости, в которую был помещен «ЛитАр», определялась только рыхлая неоформленная соединительная ткань. Фрагменты композитного 


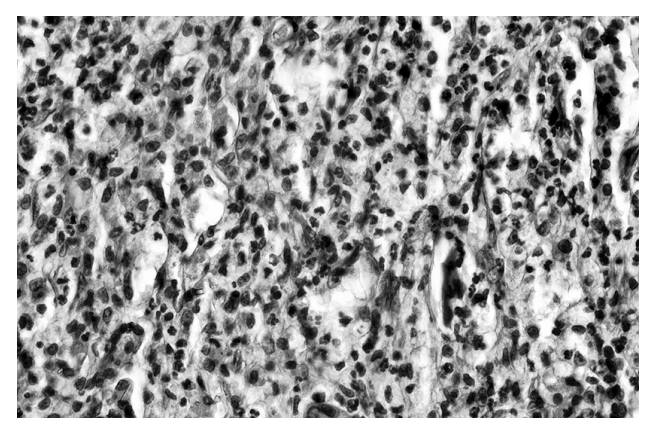

Puc. 3. Соединительная ткань, сформированная на месте ликвидированной остаточной полости при хронической эмпиеме плевры крысы. Стадия 14-х суток эксперимента (увеличение окуляра - в 10, объектива - в 40 раз)

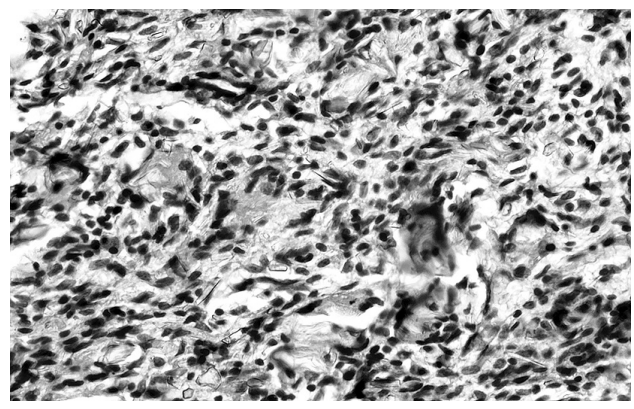

Puc. 4. Соединительная ткань, сформированная на месте ликвидированной остаточной полости при хронической эмпиеме плевры крысы. Стадия 28-х суток эксперимента (увеличение окуляра - в 10, объектива - в 40 раз)

материала в ней отсутствовали. В соединительной ткани отмечалась незначительная лейкоцитарная инфильтрация (рис. 4).

\section{Заключение}

Полученные данные свидетельствуют о том, что биодеградируемый композит «ЛитАр» в комбинации с антибиотиком значительно повышает активизацию и оптимизацию пролиферации и цитодифференцировки клеток фибробластического дифферона, вследствие чего в композитном материале выявляется большое количество дифференцированных фибробластов. В результате эффективной синтетической деятельности дифференцированных фибробластов на месте ликвидированной полости образуется рыхлая неоформленная соединительная ткань.

\section{Литература}

1. Simmers T.A., Jie C., Sie B. Paraneumonic effusions // Thorac. Cardiovasc. Surg. 2009. Vol.47, N 2. P. 77-81.

2. Rahman N.M., Davies R.J. Effusion from infections: parapneumonic effusion and empyema // Textbook of Pleural Diseases / eds R. W. Light, Y. C. G. Lee. Boca Raton, 2008. P. 341-366.

3. Цеймах Е.А., Левин А. В., Зимонин П.Е., Самуйленков А. М. Эмпиемы плевры. Частота возникновения, пункционная терапия, закрытое дренирование плевральной полости. Ч.І // Туберкулез и болезни легких. 2009. № 8. С. 3-9.

4. Coote N., Kay E.S. Surgical versus non-surgical management of pleural empyema // Cochrane Database Syst. Rev. 2009. Vol. 7, N 4.

5. Yamaguchi M., Takeo S., Suemitsu R., Matsuzawa H. Video-assisted thoracic surgery for fibropurulent thoracic empyema: a bridge to open thoracic surgery // Ann. Thorac. Cardiovasc. Surg. 2009. Vol.15, N 6. P. 368-372.

6. Пульмонология: национальное руководство / под ред. А.Г.Чучалина. М.: ГЭОТАР-Медиа, 2009. $960 \mathrm{c}$.

7. Матвеев В. Ю., Хасанов Р. М., Галков Е. М., Фахрутдинов Р. Н., Ибрагимов А. И. Комбинированное хирургическое лечение эмпиемы плевры с применением видеоторакоскопии // Практическая медицина. 2012. Т. 2, № 8. С. 111-116.

8. Фергюсон М. К. Атлас торакальной хирургии. М.: ГЭОТАР-Медиа, 2009. 304 с. 
9. Волова Л. Т. Биологическая система оценки качества биоимплантатов с помощью клеточных технологий // Успехи современного естествознания. 2008. № 5. С. 25-28.

10. Василеи В. Н., Казбанов И. В., Ефимов А. Е., Севастьянов В. И. Разработка новых методов формирования имплантационных материалов с использованием технологий электроспиннинга и биопринтирования // Вестник трансплантологии искусственных органов. 2009. Т. XI, № 2. С. 47-53.

11. Третьяков А. А., Стадников А. А., Хижняк И. И. Результаты применения композита «ЛитАр» для ликвидации остаточных полостей печени в эксперименте // Анналы хирургической гепатологии. 2013. Т. 18, № 4. С. 61-65.

12. Хижняк И. И., Третьяков А.А., Стадников А. А., Неверов А. Н. Цитоактивный композит как способ закрытия инфицированных остаточных полостей в печени в условиях эксперимента // Морфология. 2016. Т. 149, № 3. С. 219-219a.

Для цитирования: Мухаммедов Х. Б. М., Шевлюк Н. Н., Третьяков А. А., Стадников А. А., Фадеев С. Б. Метод закрытия остаточной полости композитным материалом «ЛитАр» в комбинации с антибиотиком при хронической эмпиеме плевры и особенности репаративного гистогенеза // Вестник СПбГУ. Медицина. 2017. Т. 12. Вып. 2. С. 154-160. DOI: 10.21638/11701/spbu11.2017.204

\section{References}

1. Simmers T. A., Jie C., Sie B. Paraneumonic effusions. Thorac. Cardiovasc. Surg., 2009, vol. 47, no. 2, pp. $77-81$.

2. Rahman N.M., Davies R.J.Effusion from infections: parapneumonic effusion and empyema. Textbook of Pleural Diseases. Eds R. W. Light, Y. C. G. Lee. Boca Raton, 2008, pp. 341-366.

3. Tseimakh E. A., Levin A. V., Zimonin P.E., Samuilenkov A. M.Empiemy plevry. Chastota vozniknoveniia, punktsionnaia terapiia, zakrytoe drenirovanie plevral'noi polosti. Chast' I [Empyema. The frequency of occurrence, needle therapy, closed drainage of pleural cavity. Part I]. Tuberkulez i bolezni legkikh [Tuberculosis and Lung Disease], 2009, no. 8, pp. 3-9. (In Russian)

4. Coote N., Kay E. S. Surgical versus non-surgical management of pleural empyema. Cochrane Database Syst. Rev., 2009, vol. 7, no. 4.

5. Yamaguchi M., Takeo S., Suemitsu R., Matsuzawa H. Video-assisted thoracic surgery for fibropurulent thoracic empyema: a bridge to open thoracic surgery. Ann. Thorac. Cardiovasc. Surg., 2009, vol. 15, no. 6, pp. 368-372.

6. Pul'monologiia: natsional'noe rukovodstvo [Pulmonology: national leadership]. Ed. by A. G. Chuchalin. Moscow, GEOTAR Media Publ., 2009. 960 p. (In Russian)

7. Matveev V.Iu., Khasanov R.M., Galkov E.M., Fakhrutdinov R. N., Ibragimov A.I. Kombinirovannoe khirurgicheskoe lechenie empiemy plevry s primeneniem videotorakoskopii [Combined surgical treatment of pleural empyema using VATS]. Prakticheskaia meditsina [Practical Medicine], 2012, vol. 2, no. 8, pp. 111-116. (In Russian)

8. Ferguson M.K. Thoracic surgery atlas. Saunders, 2007. 325 p. (Russ. ed.: Fergiuson M.K. Atlas torakal'noi khirurgii. Moscow, GEOTAR Media Publ., 2009. 304 p.)

9. Volova L. T. Biologicheskaia sistema otsenki kachestva bioimplantatov s pomoshch'iu kletochnykh tekhnologii [The biological system bioimplantativ quality assessment using cellular technology]. Uspekhi sovremennogo estestvoznaniia [The successes of modern science], 2008, no. 5, pp. 25-28. (In Russian)

10. Vasilets V.N., Kazbanov I. V., Efimov A. E., Sevastianov V. I. Razrabotka novykh metodov formirovaniia implantatsionnykh materialov s ispol'zovaniem tekhnologii elektrospinninga i bioprintirovaniia [Development of new methods of formation of implant materials using electrospinning technology and bioprint]. Vestnik transplantologii iskusstvennykh organov [Herald transplantology and artificial organs], 2009, vol. XI, no. 2, pp. 47-53. (In Russian)

11. Tretyakov A. A., Stadnikov A. A., Khizhniak I. I. Rezul'taty primeneniia kompozita "LitAr" dlia likvidatsii ostatochnykh polostei pecheni v eksperimente [The results of the application of the composite "LitAr" to eliminate the residual liver cavities in the experiment]. Annaly khirurgicheskoi gepatologii [Annals of surgical hepatology], 2013, vol. 18, no. 4, pp. 61-65. (In Russian)

12. Khizhniak I.I., Tretyakov A.A., Stadnikov A. A., Neverov A. N. Tsitoaktivnyi kompozit kak sposob zakrytiia infitsirovannykh ostatochnykh polostei v pecheni v usloviiakh eksperimenta [Citoactive composite as a way of closing the infected residual cavities in the liver in experiment]. Morfologiia [Morphology], 2016, vol. 149, no. 3, pp. 219-219a. (In Russian) 
For citation: Mukhammedov Kh. B. M., Shevlyuk N. N., Tretyakov A. A., Stadnikov A. A., Fadeev S. B. Method of closing the residual cavity with composite material "LitAr" in combination with an antibiotic for chronic pleural empyema and features of reparative histogenesis. Vestnik SPbSU. Medicine, 2017, vol. 12, issue 2, pp. 154-160. DOI: 10.21638/11701/spbu11.2017.204

Статья поступила в редакцию 20 декабря 2016 г.

Статья принята в печать 10 марта 2017 г.

Контактная информация:

Мухаммедов Хан Богдат Мереддурдыевич - аспирант; mb4rever@ya.ru

Шевлюк Николай Николаевич - доктор биологических наук, профессор; k_histology@orgma.ru Третьяков Анатолий Андреевич - доктор медицинских наук, профессор; anatoly-tretyakov@mail.ru

Стадников Александр Абрамович - доктор биологических наук, профессор;

alexander.stadnikov@yandex.ru

Фадеев Сергей Борисович - доктор медицинских наук; доцент; sergfsb@mail.ru

Mukhammedov Khan Bogdat M. — Postgraduate; mb4rever@ya.ru

Shevlyuk Nikolai N. - Doctor of Biology, Professor; k_histology@orgma.ru

Tretyakov Anatoly A. - MD, Professor; anatoly-tretyakov@mail.ru

Stadnikov Alexander A. - Doctor of Biology, Professor; alexander.stadnikov@yandex.ru

Fadeev Sergey B. - MD, Associate Professor; sergfsb@mail.ru 